\title{
Article \\ Implementation of Portable Automatic Tourniquet with High-Elasticity Biocompatible Strap
}

\author{
Seong Tak Woo ${ }^{1}$, Cheol Woo Park ${ }^{2,3}$, Ji Hyun Sung ${ }^{4}$ and Cheol-Min Park ${ }^{5,6, *(1)}$ \\ 1 Department of Electronic Engineering, Dong Seoul University, 76 Bokjeong-ro, Sujeong-gu, \\ Seongnam-si 13117, Korea; stwoo@du.ac.kr \\ 2 Medivice Incorporated, 61 Daehak-ro, Gumi 39177, Korea; pcwno1@gmail.com \\ 3 R\&D Center, Medivice Incorporated, 60 Beoman-ro, Suseong-gu, Daegu 42242, Korea \\ 4 Mechanical Components and Materials R\&D Group, Korea Institute of Industrial Technology (KITECH), \\ 320 Techno Sunhwan-ro, Daegu 42994, Korea; jsung@kitech.re.kr \\ 5 School of Materials Science and Engineering, Kumoh National Institute of Technology, 61 Daehak-ro, \\ Gumi 39177, Korea \\ 6 Department of Energy Engineering Convergence, Kumoh National Institute of Technology, 61 Daehak-ro, \\ Gumi 39177, Korea \\ * Correspondence: cmpark@kumoh.ac.kr; Tel.: +82-54-478-7746
}

Citation: Woo, S.T.; Park, C.W.; Sung J.H.; Park, C.-M. Implementation of Portable Automatic Tourniquet with High-Elasticity Biocompatible Strap. Appl. Sci. 2021, 11, 4653. https:// doi.org/10.3390/app11104653

Academic Editor: Richard Yong Qing Fu

Received: 21 April 2021

Accepted: 17 May 2021

Published: 19 May 2021

Publisher's Note: MDPI stays neutral with regard to jurisdictional claims in published maps and institutional affiliations.

Copyright: (c) 2021 by the authors. Licensee MDPI, Basel, Switzerland. This article is an open access article distributed under the terms and conditions of the Creative Commons Attribution (CC BY) license (https:// creativecommons.org/licenses/by/ $4.0 /)$.

\begin{abstract}
The most common screening techniques to diagnose a patient's illness are blood collection and intravenous procedures. To find a collection or injection site, conventional blood collection support tools, such as latex tubing and buckle-type tourniquets, are generally used to compress the patient's blood vessels. This conventional passive method has significant problems such as latex allergy, vulnerability to site contamination and potential bloodstream infection, and physical damage due to improper use. To overcome the disadvantages of conventional blood collection support tools, an automatic tourniquet with a high-elasticity biocompatible strap was constructed. The automatic tourniquet is designed to automatically adjust the strap length using a motor to control the pressure according to the body dimensions of patients. In order to evaluate the performance of the automatic tourniquet, blood flow characteristics were analyzed using an ultrasound measurement system. The results demonstrated that the automatic tourniquet showed better performance compared with those of other blood collection support tools.
\end{abstract}

Keywords: tourniquet; biocompatible strap; blood control; portable auto-tourniquet; blood velocity

\section{Introduction}

Recently, medical technologies have attracted much attention due to rapid technological development. Among medical technologies, basic screening techniques to diagnose a patient's illness are crucial. The most common screening method is through blood collection using an intravenous procedure. In general, conventional blood collection support tools such as latex tubing and buckle type-tourniquets are used to compress the patient's blood vessels [1-8]. These conventional blood collection methods are operated using passive methods in which medical staff directly apply the tourniquet to the patient's limb. Long-term use of tourniquets can lead to physical damage such as hemolysis due to blood vessel compression. Furthermore, according to some research results, the reuse of the latex tubing tourniquets may threaten patients' safety (e.g., leading to site contamination and potential bloodstream infection); therefore, such material should be supplemented accordingly [9-11]. In addition, some latex allergy sufferers may experience allergic shock [12-16]. To solve these problems, in some countries single-use tourniquets (e.g., the Tournistrip device (Iskus Health Ltd., Ireland)) have been used for many years. Similar tourniquets are easy to tighten and adjust, and their position on the same patient can be changed; moreover, unlike some rubber-band designs, they do not pinch the patient's skin. Nev- 
ertheless, medical staff have also expressed the need for fully automatic devices with single-use tourniquets.

In this study, to overcome the disadvantages of conventional blood collection support tools, an automatic tourniquet was successfully implemented. It automatically compresses the limb in preparation for blood collection and is easily operated. Therefore, the damage caused by improper tourniquet use by medical staff, such as latex allergy, site contamination, and potential bloodstream infection, will be reduced significantly. Additionally, a high-elasticity biocompatible strap has been used for the automatic tourniquet. Therefore, it can be used for some patients with a latex allergy. Specifically, among the various materials available, a thermoplastic elastomer (TPE) strap was selected on the basis of the experimental results. The proposed automatic tourniquet was designed to automatically adjust the strap length through the activation of a direct current (DC) motor. This mechanism was developed based on the current control of the system main controller. To evaluate the performance of the automatic tourniquet, blood flow characteristics were verified using ultrasound equipment and compared with the conventional blood collection support tools of latex tube and buckle-type tourniquet.

\section{Methods}

\subsection{Configuration of an Auto-Tourniquet System}

The prototype automatic tourniquet system and concept image of the final automatic tourniquet system are shown in Figure 1a,b, respectively. The length and tension of the strap are controlled using a DC motor integrated in the system. The pressure of the automatic tourniquet is designed to be selected from five different settings. The tension of the strap is controlled through system signal processing, and the tension level can be confirmed through the display module.

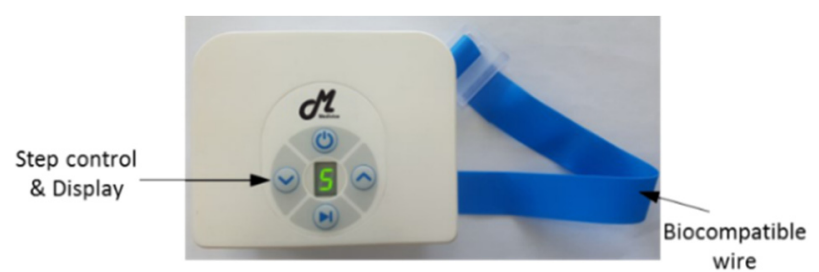

(a)

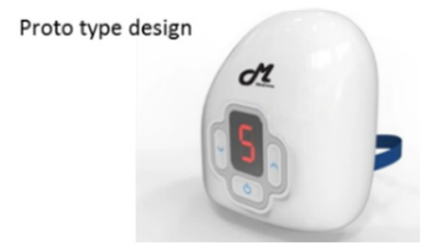

(b)

Figure 1. Proposed automatic tourniquet system: (a) prototype automatic tourniquet system; (b) concept image of the final automatic tourniquet system.

\subsection{Biocompatible Strap with High Elasticity}

The material used for the strap in an automatic tourniquet is important because it is in direct contact with the human body. Therefore, the development of a biocompatible strap is important. Additionally, the strap also needs the mechanical properties of high elasticity and tensile strength, which result in superior hemostatic properties when applied to patients. The elongation characteristics of various strap materials were evaluated using a Push-Pull Gauge (Attonic ARF-50), and the optimum strap material, with excellent temperature and tensile strength characteristics, was selected. Generally, the tourniquet is used at room temperature $\left(5 \sim 35{ }^{\circ} \mathrm{C}\right)$, but it may be used in situations of 
extreme temperatures $[17,18]$. Here, we used a thermo-mechanical analyzer (TMA) (Q400 TMA, TA Instruments, USA) to evaluate the temperature characteristics of straps. Notably, TMA are generally employed to measure the deformation of samples over a wide range of temperatures.

Latex tubing made of rubber material is typically used as a conventional hemostatic substitute strap, and it exhibits somewhat superior characteristics in terms of tensile strength. However, the latex causes an allergic reaction in some patients, and has poor wearability because of the high friction coefficient of the latex. Alternatively, buckle-type tourniquets can be used for urgent hemostasis in field situations rather than being used in a hospital. These are inconvenient due to the need for manual operation and the inadequate strap material. In this paper, the temperature characteristics of straps were evaluated to determine the optimal strap for the proposed automatic tourniquet system. The experimental environment for evaluating the temperature characteristics for each material using TMA is shown in Figure 2, and the TMA results are shown in Figure 3.

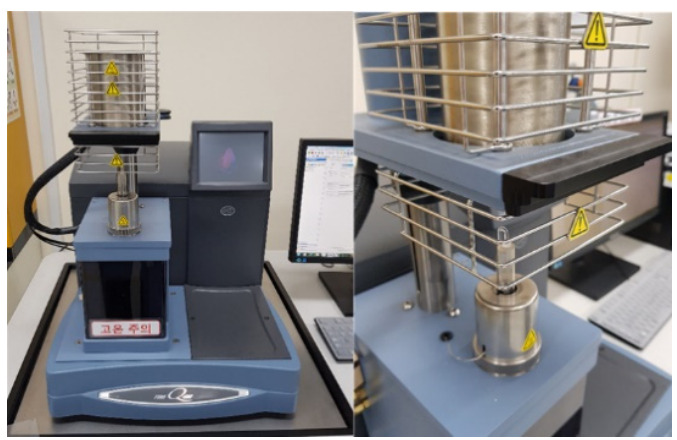

Figure 2. Environment of thermal test for various straps by TMA.

(a)

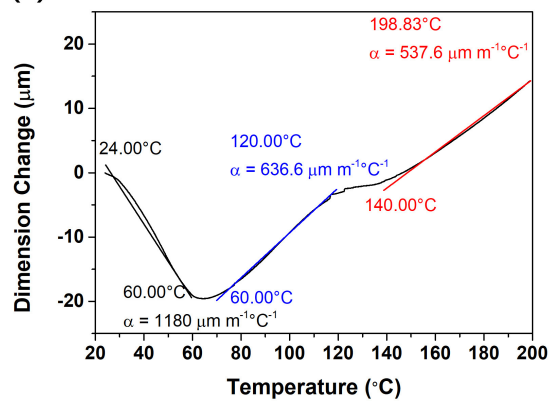

(c)

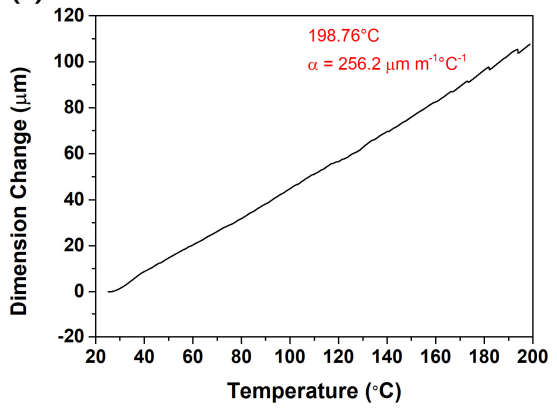

(b)

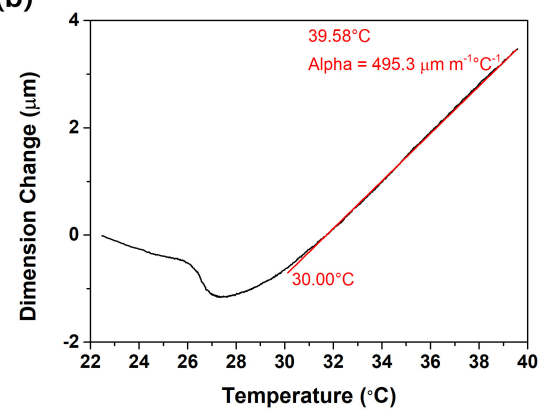

(d)

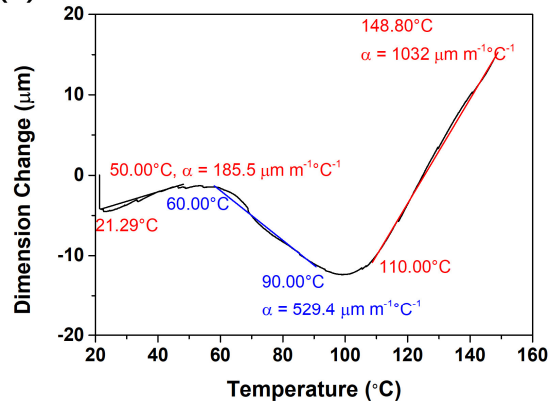

Figure 3. TMA analysis results for various straps: (a) Teflon; (b) latex tube; (c) silicone tube; and (d) thermoplastic elastomer.

The temperature and dimension changes of various strap materials, consisting of Teflon, latex tube, silicone tube, and thermoplastic elastomer, were analyzed by TMA. Although the appropriate temperature range of the practical use of straps is $20-40^{\circ} \mathrm{C}$, the straps were analyzed to investigate their thermal stability at a wide temperature range. 
On the basis of the thermal stability of the straps, the temperature ranges were determined and analyzed. Teflon has a thermal expansion coefficient $(\alpha)$ of $1180 \mu \mathrm{m}$ in the temperature range from 20 to $60^{\circ} \mathrm{C}$, which shows that it displays large thermal deformation. The latex tube used widely as a conventional tourniquet has an $\alpha$ of $495.3 \mu \mathrm{m}$ in the temperature range from 27 to $40{ }^{\circ} \mathrm{C}$. Although latex tube is widely used currently, it displays large thermal deformation at a narrow service temperature range. The silicone tube has an $\alpha$ of $296.3 \mu \mathrm{m}$ in the temperature range from 20 to $200{ }^{\circ} \mathrm{C}$, indicating that the thermal deformation is relatively small. Finally, TPE as proposed in this paper has the most stable $\alpha$ compared with the other materials: $185.5 \mu \mathrm{m}$ in the temperature range from 20 to $60^{\circ} \mathrm{C}$. In short, TPE is the most suitable material for use as an automatic tourniquet strap when considering the temperature range of practical use $\left(20-40{ }^{\circ} \mathrm{C}\right)$.

To determine the optimal strap (i.e., wire) for the automatic tourniquet system, the mechanical properties of straps made of six different materials (i.e., Teflon, PVC, latex, TPE, PE, silicone) were analyzed by a universal testing machine (i-UT50, Excelab, Republic of Korea) (results in Figure 4). The elongation was measured by applying a constant force of $1.5 \mathrm{kgf}$. The specific experimental conditions were as follows: dimension of the materials, $50 \mathrm{~mm}^{2}$; speed, $10 \mathrm{~mm} / \mathrm{min}$; gauge distance, $20 \mathrm{~mm}$. Although Teflon had the highest tensile strength of $2.10 \mathrm{MPa}$, TPE had the highest strain-rate of 3.3 times and an elastic modulus of $0.30 \mathrm{kgf}$, with a high tensile strength of $2.05 \mathrm{MPa}$, as shown in Table 1. Additionally, TPE was highly wearable for skin. In conclusion, TPE has the highest mechanical properties among various strap materials, which demonstrates that TPE is an excellent material for tourniquet straps.

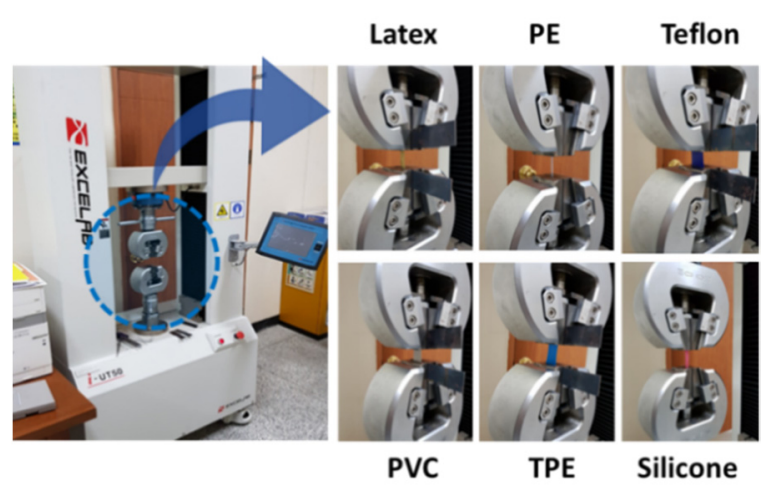

Figure 4. The tensile strength device and photograph of experimental environment for each material.

Table 1. The elasticity properties of the straps.

\begin{tabular}{ccccc}
\hline Material & $\begin{array}{c}\text { Strain Rate } \\
\text { (Times) }\end{array}$ & $\begin{array}{c}\text { Elastic Modulus } \\
\mathbf{( k g f / c m )}\end{array}$ & $\begin{array}{c}\text { Tensile Strength } \\
\mathbf{( M P a )}\end{array}$ & $\begin{array}{c}\text { Wearable for } \\
\text { Skin }\end{array}$ \\
\hline Teflon & 1.2 & 0.10 & 2.10 & Middle \\
PVC & 1.4 & 0.15 & 1.95 & Middle \\
Latex & 2.1 & 0.20 & 1.58 & Middle \\
TPE & 3.3 & 0.30 & 2.05 & High \\
PE & 2.5 & 0.25 & 2.00 & High \\
Silicone & 1.5 & 0.16 & 2.00 & Low \\
\hline
\end{tabular}

On the basis of the mechanical properties, TPE was selected for the auto-tourniquet system in this study. In general, TPE can support the needs of medical device development from virtually every angle. The TPE measured was a standard product based on ISO 10993 biocompatibility standards [19-21]. 


\subsection{Fabricated Automatic Tourniquet System}

The operation of the automatic tourniquet is shown in Figure 5. The TPE strap was applied to the patient, and the operation was started after checking whether the strap was connected by using the load cell (BF1000, Zemic Europe, Netherlands) in the device.

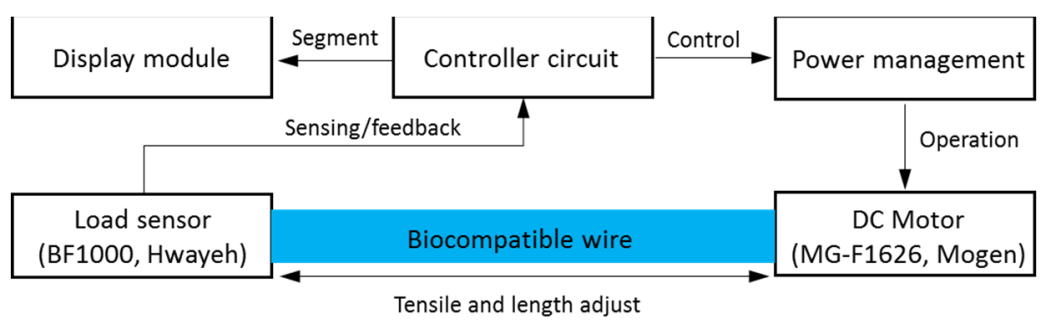

(a)

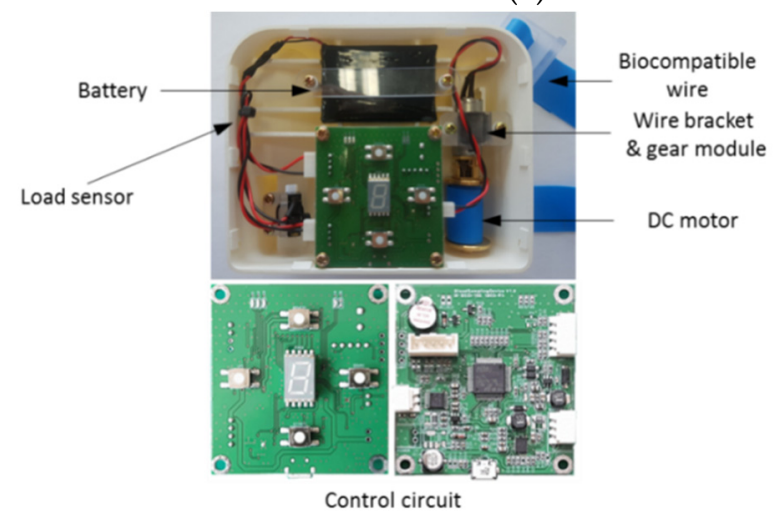

(b)

Figure 5. (a) Block diagram and (b) structure of proposed auto-tourniquet system.

The motor (MG-F1626, Mogen, Republic of Korea) in the device is designed for $9 \mathrm{~V}$ operation, with a rated current of $60 \mathrm{~mA}$ and a gear ratio of $1 / 60$. Figure $5 \mathrm{~b}$ shows the inside of the system, so that it is easy to understand the hardware configuration of the automatic tourniquet, which consists of the battery, motor, and PCB. The automatic tourniquet system can be charged using the LTC4054 charger, and can be fully charged within $3 \mathrm{~h}$ under conditions of $12 \mathrm{~V}$ and $1.5 \mathrm{~A}$. To ensure the operating efficiency of the system, a $7.4 \mathrm{~V}$ $1250 \mathrm{mAh}$ Li polymer battery was used. The battery size was $6.5 \times 51 \times 73 \mathrm{~mm}$, which fit easily into the system case.

\subsection{Experimental Procedure}

To confirm the applicability of the proposed automatic tourniquet system, it was applied to the control group of five human subjects. First, a latex tube, a buckle-type tourniquet, and a portable automatic tourniquet were placed on one of the subject's upper extremities. Then, the blood flow velocity under varying degrees of compression was measured by a medical doctor using an ultrasonic device (Acuson Sequoia c512, Siemens Healthcare GmbH, Germany). Straps (e.g., single-use tourniquets) are generally placed on the median cubital or cephalic veins for the sake of hemostasis [22,23]. Clinical experimentation upon the health control group of this study was performed with prior approval from the Institutional Review Board of Bioethics (IRB No. 1041459-202011-HR003-01). In this experiment, the cephalic vein was squeezed in all cases and the blood flow velocity in the median cubital vein was measured. Experiments were performed on three adult males and two adult females, and repeated five times at $30 \mathrm{~min}$ intervals for each patient. The experimental environment for the evaluation is shown in Figure 6, 
and information about the subjects is shown in Table 2. Normal state and pressure were compared and the auto-tourniquet was measured at tension settings 1,3, and 5.
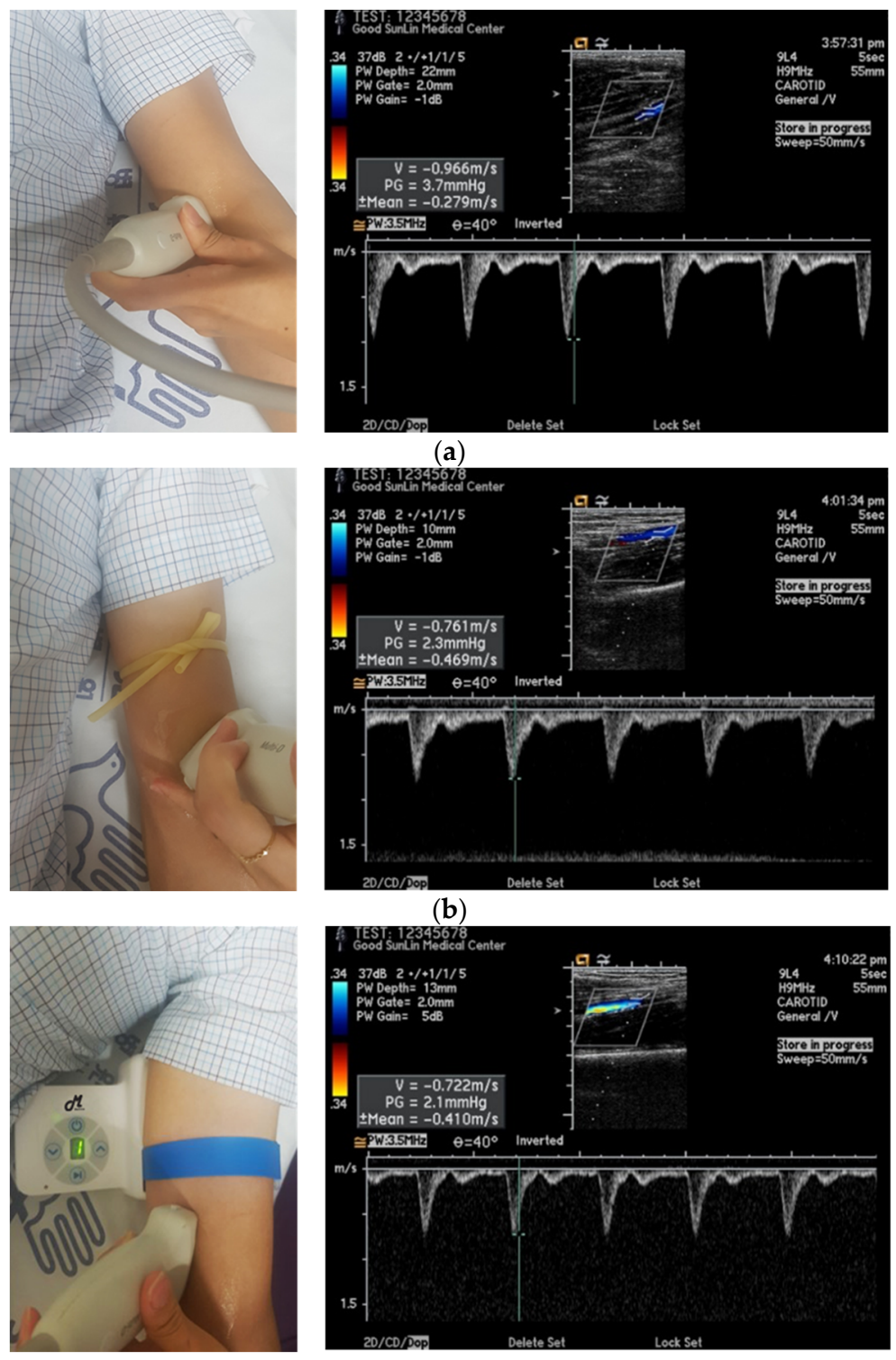

(c)

Figure 6. Experimental environment photograph and measurement picture of blood flow velocity using ultrasonic equipment: (a) normal; (b) using the latex tube; (c) using the fabricated automatic tourniquet.

Table 2. The healthy control group information.

\begin{tabular}{ccccc}
\hline Sex & Weight $(\mathbf{c m})$ & Height $\mathbf{( k g )}$ & Age & Disease \\
\hline \multirow{3}{*}{ Male } & 173 & 81 & 32 & None \\
& 172 & 73 & 42 & None \\
& 168 & 75 & 50 & None \\
\hline \multirow{2}{*}{ Female } & 159 & 49 & 24 & None \\
& 164 & 55 & 30 & None \\
\hline
\end{tabular}




\section{Experimental Results}

\subsection{Results of Blood Flow Control}

The blood flow control characteristics of the proposed automatic tourniquet are shown in Table 3 and Figure 7a. In particular, Table 3 shows the velocity of blood flow measured when applying latex tubing and the automatic tourniquet to each of the five members of the control group. For the conventional latex tube tourniquet, the compression level $(1.5 \sim 2 \mathrm{~N})$ for blood sampling was uniformly adjusted [24,25]. Blood flow velocities in the normal state, measured on the subjects' median cubital vein, were measured to be $0.950 \mathrm{~m} / \mathrm{s}$ on average. In addition, when the latex tubing was applied, the measured blood flow velocities averaged $0.760 \mathrm{~m} / \mathrm{s}$. In the control group, blood velocities were measured to be somewhat lower in female than male subjects. In the case of the automatic tourniquet, it was adjusted to tension steps 1 to 5 . When the automatic tourniquet was used at tension steps 1 to 5 , the means of the corresponding blood flow velocities were $0.806 \mathrm{~m} / \mathrm{s}, 0.593 \mathrm{~m} / \mathrm{s}, 0.533 \mathrm{~m} / \mathrm{s}, 0.425 \mathrm{~m} / \mathrm{s}$, and $0.310 \mathrm{~m} / \mathrm{s}$, respectively. The experiment using the proposed system was measured repeatedly, five times for each step, and was performed after the subject took sufficient rest at 30 min intervals.

Table 3. Results of blood flow velocity with the healthy control group according to the pressure method (the blood flow velocities were measured using the ultrasonic measurement system).

\begin{tabular}{|c|c|c|c|c|c|c|c|}
\hline \multirow{2}{*}{$\begin{array}{l}\text { Control } \\
\text { Group }\end{array}$} & \multirow{2}{*}{$\begin{array}{c}\text { Normal (m/s), } \\
\text { Mean }(\mathrm{N}=5) \\
\text { (Min-Max) }\end{array}$} & \multirow{2}{*}{$\begin{array}{c}\text { Latex Tubing } \\
(\mathrm{m} / \mathrm{s})(\mathrm{N}=1) \\
(\mathrm{Min}-\mathrm{Max})\end{array}$} & \multicolumn{5}{|c|}{ Proposed Automatic Tourniquet $(\mathrm{m} / \mathrm{s})$, Mean $(\mathrm{N}=5)$} \\
\hline & & & $\begin{array}{c}\text { Step } 1 \\
\text { (Min-Max) }\end{array}$ & $\begin{array}{c}\text { Step } 2 \\
\text { (Min-Max) }\end{array}$ & $\begin{array}{c}\text { Step } 3 \\
\text { (Min-Max) }\end{array}$ & $\begin{array}{c}\text { Step } 4 \\
\text { (Min-Max) }\end{array}$ & $\begin{array}{c}\text { Step } 5 \\
\text { (Min-Max) }\end{array}$ \\
\hline \multirow{6}{*}{ Male } & 0.946 & & 0.764 & 0.590 & 0.557 & 0.454 & 0.316 \\
\hline & $(0.917-0.980)$ & 0.845 & $(0.717-0.896)$ & $(0.567-0.610)$ & $(0.522-0.600)$ & $(0.420-0.489)$ & $(0.293-0.377)$ \\
\hline & 1.034 & & 0.884 & 0.579 & 0.523 & 0.468 & 0.334 \\
\hline & $(0.974-1.064)$ & 0.76 & $(0.738-0.940)$ & $(0.560-0.602)$ & $(0.501-0.581)$ & $(0.430-0.482)$ & $(0.310-0.380)$ \\
\hline & 0.915 & & 0.789 & 0.597 & 0.559 & 0.447 & 0.320 \\
\hline & $(0.901-0.933)$ & 0.773 & $(0.721-0.850)$ & $(0.564-0.622)$ & $(0.510-0.596)$ & $(0.404-0.490)$ & $(0.286-0.361)$ \\
\hline \multirow{4}{*}{ Female } & 0.967 & & 0.712 & 0.612 & 0.521 & 0.405 & 0.324 \\
\hline & $(0.930-1.006)$ & 0.710 & $(0.672-0.830)$ & $(0.592-0.624)$ & $(0.490-0.587)$ & $(0.384-0.477)$ & $(0.294-0.350)$ \\
\hline & 0.888 & 0714 & 0.854 & 0.595 & 0.504 & 0.354 & 0.257 \\
\hline & $(0.851-0.920)$ & 0.714 & $(0.658-0.896)$ & $(0.565-0.618)$ & $(0.480-0.556)$ & $(0.320-0.457)$ & $(0.210-0.328)$ \\
\hline \multirow{2}{*}{ Mean } & 0.950 & 0.760 & 0.806 & 0.593 & 0.533 & 0.425 & 0.310 \\
\hline & $(0.851-1.064)$ & $(0.710-0.845)$ & $(0.658-0.940)$ & $(0.560-0.624)$ & $(0.480-0.600)$ & $(0.320-0.490)$ & $(0.210-0.380)$ \\
\hline
\end{tabular}

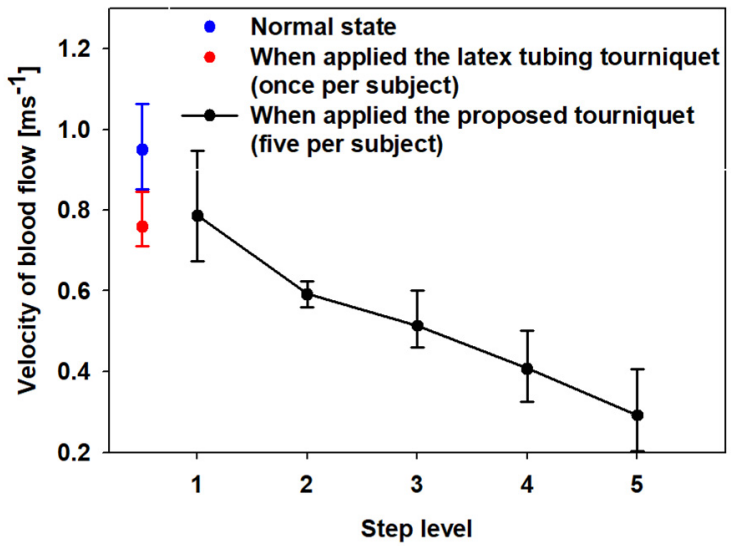

(a)

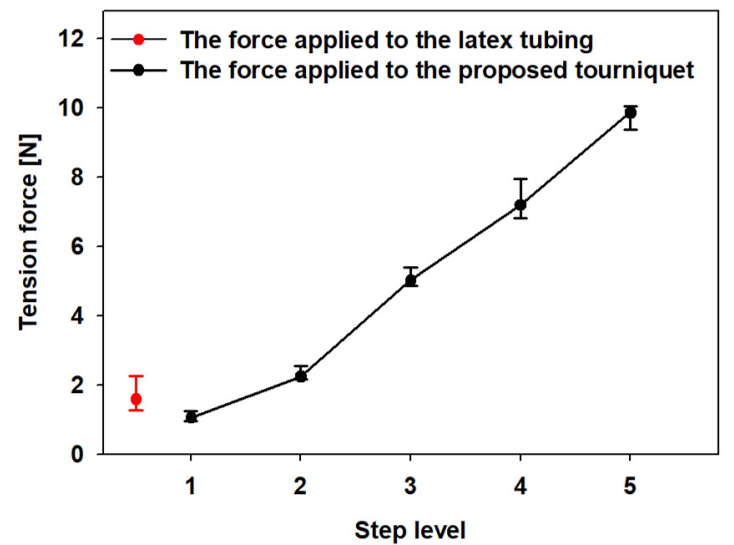

(b)

Figure 7. Experimental results of (a) the velocity of blood flow and (b) tension force using the proposed tourniquet and the latex tubing. (The blue dot indicates blood velocity in normal state, the red dot indicates velocity of blood flow and tension force when the cephalic vein is compressed using the latex tube tourniquet). 
It was confirmed that blood flow was controlled quantitatively according to the pressure intensity, although there was some difference according to the physical characteristics and the experimental environment of the healthy control group. The results demonstrate that the velocities of blood flow were maintained at more than $6 \mathrm{~dB}$ higher at the maximum pressure state, compared with those of the conventional latex tube tourniquet.

The tensile strength of the automatic tourniquet, which was measured using a PushPull Gauge (ARF-50, Attonic, Japan), is compared in Figure 7b. The force of the proposed tourniquet measured at tension steps 1 to 5 was measured as $0.9,2.1,4.9,7.1$, and $9.9 \mathrm{~N}$, respectively. The tension force test using the push-pull gauge was less error-free than the ultrasonic test because there was no significant variation in the experimental environment.

\subsection{System Charge Property}

In the characteristics of the proposed tourniquet system, another important point may be the operating time of the system. In particular, as a healthcare device, the characteristics of the battery are also included as an important factor. The operating time of the prototype automatic tourniquet system is affected by the battery and charging circuit. The battery used in the automatic tourniquet was a Li polymer battery $(7.4 \mathrm{~V}, 1250 \mathrm{mAh})$. In this study, the characteristics of the applied battery were analyzed using a battery cycling tester, with results shown in Figure 8.

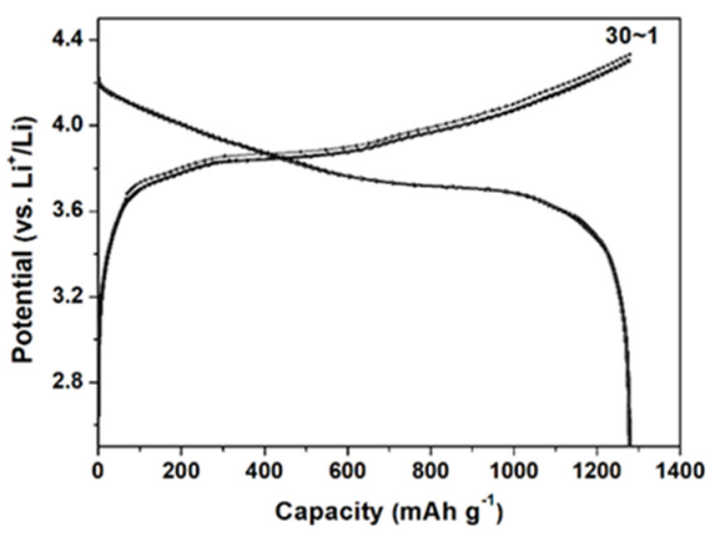

(a)

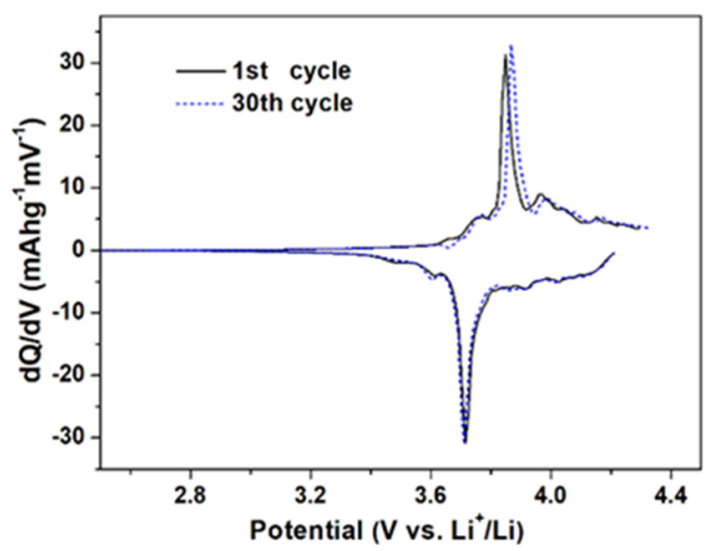

(b)

Figure 8. The battery properties of the automatic tourniquet: (a) potential capacity; and (b) differential capacity.

As shown in Figure $8 \mathrm{a}, \mathrm{b}$, the average potential of the battery was approximately $3.8 \mathrm{~V}$ and its cycling performance was very stable after 30 cycles. From the experimental results, the battery shows stable characteristics, which are applicable to the system in practice to enable safe operation. The operating time and power consumption characteristics of the portable automatic tourniquet system based on the evaluated battery were measured and the results are shown in Figure 9.

The current and power for devices operating at tension step 5 (9.9 $\mathrm{N}$ load) were measured. The current was measured to be about $20 \mathrm{~mA}$ in the standby state and about $42 \mathrm{~mA}$ after an average of $13 \mathrm{~h}$ in operation. The battery capacity of the device is $670 \mathrm{mAh}$, and it can operate for $15 \mathrm{~h}$ considering the measured current.

Considering external environmental factors such as the charge state and the temperature during use, the measured operating time characteristic is expected to be similar to the theoretical calculated time range. In addition, the blood collection equipment used in a hospital is in operation only when collecting blood and is in a charged state at other times. Therefore, the manufactured device's performance of $13 \mathrm{~h}$ of operation without external charging can be applied in practical use. 


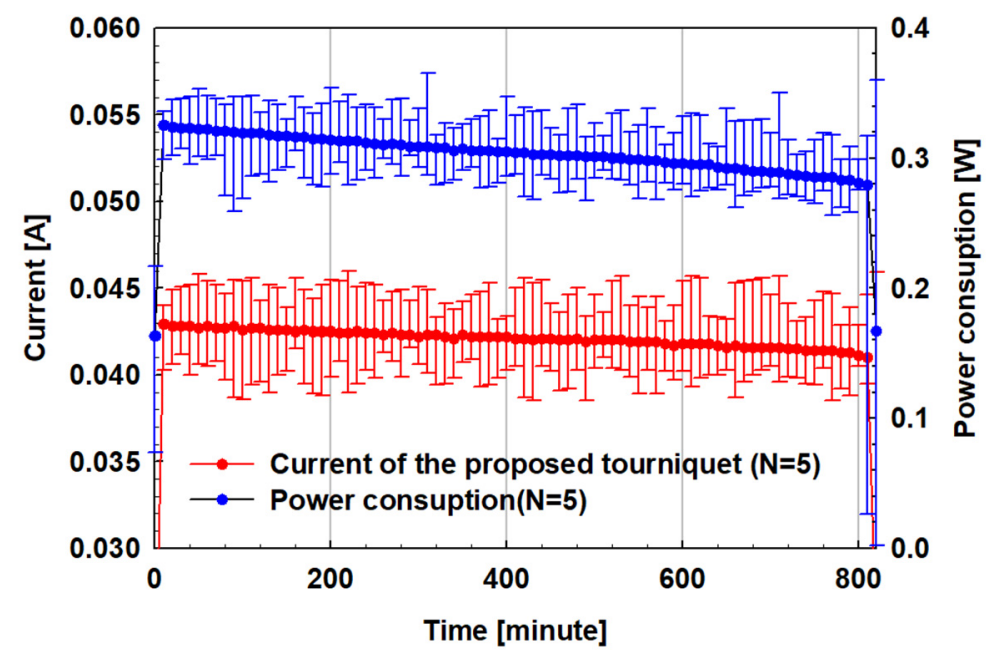

Figure 9. Power consumption characteristics of the prototype automatic tourniquet.

In this paper, a TPE strap with excellent mechanical and biocompatible properties was used in an automatic tourniquet device. The device also comprised a module composed of a low-power motor, a sensor, and a signal processing circuit. The functions of the module were evaluated quantitatively using an ultrasonic blood flow measuring instrument. The controllability of the automatic tourniquet during a conventional blood collection setup was superior to those of a latex tube or buckle-type tourniquet. In particular, the built-in charging and intensity-control function in the system module have superior features over those of conventional methods.

\section{Discussion}

We expect that the portable automatic tourniquet device described in this paper will be highly useful in a complicated operating room, battlefield, or emergency environment. The proposed automatic tourniquet system incorporates a biocompatible TPE strap. This material has been shown to have a tensile strength of about 2.05 MPa through experiments; its mechanical properties are superior to the $1.58 \mathrm{MPa}$ of conventional latex tubing. As mentioned in the introduction, some countries use a single-use tourniquet of latex-free material such as Tournistrip to reduce cross-infection and other damage. It is applied manually by wrapping it around a patient's arm and fixing it. While this approach is not inconvenient, some medical staff require a portable automatic tourniquet. The automatic tourniquet system of this study is designed to control the pressure on the hemostasis area by adjusting the length of the strap in five steps. It functions quantitatively and conveniently in comparison with other more conventional methods, but the pressure applied depends on the patient's body type and may vary from person to person. As shown in Figure 5b, it is possible to measure the pressure level through a load sensor for feed-back, but it may be difficult to finely adjust the tension because this would require lowering one of the five steps. Therefore, in future research, implementation should enable fine tension control by configuring many steps. In addition, if fine pressure control is required for surgery, it may be desirable to use a pneumatic tourniquet. The pneumatic tourniquet is relatively bulky and consumes large amounts of current but has a linear tension control characteristic. However, for pneumatic tourniquets used in operating rooms, improvement is needed to reduce volume, power, and weight for use in complex spaces [26-28].

In this study, the proposed automatic tourniquet system is designed to replace existing latex tubing with a function for simple hemostasis or compression, and to be used conveniently by medical staff. If test results validate a fine tension control function and more health control groups endorse the proposed portable tourniquet system in the future, it may serve as a replacement for the pneumatic tourniquet. The proposed system is designed 
to operate with a built-in charging circuit and to sustain maximum tension for about $13 \mathrm{~h}$, which can be enough for hospital use.

The proposed system is an electronic medical device that requires an environmental reliability evaluation for electromagnetic interference (EMI), cytotoxicity, and user stability as well as operational reliability. In a previous study, the control of tensile strength and blood flow velocity by a health control group using a TPE strap was confirmed, but for a tourniquet of the proposed structure to be used in hospitals, additional evaluations will have to be made.

\section{Conclusions}

In this study, an automatic tourniquet system with a biocompatible strap wire and a direct current motor was constructed and its performance was verified. The system's DC motor adjusts the length of the TPE strap wrapped around the patient's arm, and thus the pressure in the area where the strap is wound is indirectly increased to control blood flow velocity. We selected a strap wire with a tensile strength of about $2.05 \mathrm{MPa}$ using a tension testing machine and incorporated it into the system.

The system was applied to a control group of five healthy subjects and its control of blood flow velocity was measured with an ultrasonic device. Our system compared favorably with the widely used latex tubing and buckle-type tourniquet. The results of our previous research will be effective in emergency situations such as simple hemostasis, complex operating rooms, and battle conditions in the future. It is understood that it must undergo certification as a medical device and must undergo a standard test evaluation as a medical electronic device. In addition, it is necessary to improve the system by testing it with more users. We look forward to performing further research to support these developmental steps.

Author Contributions: Study design, measurements, data analysis, and discussion by S.T.W., C.W.P., J.H.S. and C.-M.P. Blood velocity experimental based on the healthy control group by S.T.W. and C.W.P. All authors have approved the submitted manuscript, the manuscript has not been submitted elsewhere nor published. All authors have read and agreed to the published version of the manuscript.

Funding: This research was supported by Basic Science Research Program through the National Research Foundation of Korea (NRF) funded by the Ministry of Education (No. 2018R1D1A1B07051072 and 2019S1A5A2A03054267). This research was also supported by the MSIT (Ministry of Science and ICT), Korea, under the Grand Information Technology Research Center support program (IITP2021-2020-0-01612) supervised by the IITP (Institute for Information \& Communications Technology Planning \& Evaluation).

Institutional Review Board Statement: The study was conducted according to the guidelines of the Declaration of Helsinki, and approved by the Institutional Review Board of Gyungil University (protocol code 1041459-202012-HR-003-01 and 29 Nov. 2020 to 28 Nov. 2021 of approval).

Informed Consent Statement: Informed consent was obtained from all subjects involved in the study.

Conflicts of Interest: The authors declare that there is no conflict of interest regarding the publication of this paper.

\section{References}

1. Kragh, J.F.; Walters, T.J.; Baer, D.G.; Fox, C.J.; Wade, C.E.; Salinas, J.; Holcomb, J.B. Survival with Emergency Tourniquet Use to Stop Bleeding in Major Limb Trauma. Ann. Surg. 2009, 249, 1-7. [CrossRef]

2. Aglietti, P.; Baldini, A.; Vena, L.; Abbate, R.; Fedi, S.; Falciani, M. Effect of Tourniquet Use on Activation of Coagulation in Total Knee Replacement. Clin. Orthop. Relat. Res. 2000, 371, 169-177.

3. Kam, P.C.A.; Kavanaugh, R.; Yoong, F.F.Y. The arterial tourniquet: Pathophysiological consequences and anaesthetic implications. Assoc. Anaesth. 2001, 56, 534-545. [CrossRef] [PubMed]

4. McEwen, J.A.; Kelly, D.L.; Jardanowski, T.; Inkpen, K. Tourniquet Safety in Lower Leg Applications. Orthop. Nurs. 2002, 21, 61-62. [CrossRef] [PubMed]

5. Pauers, R.S.; Carocci, M.A. Low pressure pneumatic tourniquets: Effectiveness at minimum recommended inflation pressures. J. Foot Ankle Surg. 1994, 33, 605-609. 
6. Noordin, S.; McEwen, J.A.; Kragh, C.J.F.; Eisen, A.; Masri, B.A. Surgical Tourniquets in Orthopaedics. J. Bone Jt. Surg. 2009, 91, 2958-2967. [CrossRef] [PubMed]

7. Lourenco, E.S.; Cortes, J.; Costa, J.; Linhares, A.; Alves, G. Evaluation of Commercial Latex as a Positive Control for In Vitro Testing of Bioceramics. Key Eng. Mater. 2014, 631, 357-362. [CrossRef]

8. Hwang, C.J.; Cha, J.Y. Mechanical and biological comparison of latex and silicone rubber bands. Am. J. Orthod. Dentofac. Orthop. 2003, 124, 379-386. [CrossRef]

9. Parreira, P.; Serambeque, B.; Costa, P.S.; Monico, L.S.; Oliveira, V.; Sousa, L.B.; Gama, F.; Bernardes, A.R.; Adriano, D.; Marques, A.I.; et al. Impact of an Innovative Securement Dressing and Tourniquet in Peripheral Intravenous Catheter-Related Complications and Contamination: An Interventional Study. Int. J. Environ. Res. Public Health 2019, 16, 3301. [CrossRef]

10. Salgueiro-Oliveira, A.; Oliveira, V.; Costa, P.; Gama, F.; Graveto, J.; Parreira, P.; Osorio, N. Tourniquets used in peripheral venipuncture as a potential vehicle for transmission of microorganisms: Scoping review. Infectio 2020, 24, 92-97. [CrossRef]

11. Salgueiro-Oliveira, A.; Costa, P.J.S.; Braga, L.M.; Graveto, J.M.G.N.; Oliveira, V.S.; Perreira, P.M.S.D. Health professionals' practices related with tourniquet use during peripheral venipuncture: A scoping review. Rev. Lat. Am. Enferm. 2019, 27, e3125. [CrossRef]

12. Crippa, M.; Belleri, L.; Mistrello, G.; Tedoldi, C.; Alessio, L. Prevention of latex allergy among health care workers and in the general population: Latex protein content in devices commonly used in hospitals and general practice. Int. Arch. Occup. Environ. Health 2006, 79, 550-557. [CrossRef]

13. Allmers, H.; Schmengler, J.; Skudlik, C. Primary prevention of natural rubber latex allergy in the German health care system through education and intervention. J. Allergy Clin. Immunol. 2002, 110, 318-323. [CrossRef]

14. Bousquet, J.; Flahault, A.; Vandenplas, O.; Ameille, J.; Duron, J.J.; Perquet, C.; Chevrie, K.; Annesi-Maesano, I. Natural rubber latex allergy among health care workers: A systematic review of the evidence. J. Allergy Clin. Immunol. 2006, 118, 447-454. [CrossRef]

15. Taylor, J.S.; Erkek, E. Latex allergy: Diagnosis and management. Dermatology 2004, 17, 289-301. [CrossRef]

16. Reines, H.D.; Seifert, P.C. Patient Safety: Latex Allergy. Surg. Clin. N. Am. 2005, 85, 1329-1340. [CrossRef]

17. Dhillion, B.S. Medical Device Reliability and Associated Areas; CRC Press: Boca Raton, FL, USA, 2000; pp. 89-99.

18. Webster, J.G. Medical Instrumentation Application and Design; John Wiley and Sons Inc.: Hoboken, NJ, USA, 2008 ; pp. 119-128.

19. Fray, M.E.; Prowans, P.; Puskas, J.E.; Altstadt, V. Biocompatibility and Fatigue Properties of Polystyrene, Polyisobutylene, Polystyrene, an Emerging Thermoplastic Elastomeric Biomaterial. Biomacromolecules 2006, 7, 844-850. [CrossRef]

20. Guillemette, M.D.; Roy, E.; Auger, F.A.; Veres, T. Rapid isothermal substrate microfabrication of a biocompatible thermoplastic elastomer for cellular contact guidance. Acta Biomater. 2011, 7, 2492-2498. [CrossRef]

21. Puskas, J.E.; Chen, Y. Biomedical Application of Commercial Polymers and Novel Polyisobutylene-Based Thermoplastic Elastomers for Soft Tissue Replacement. Biomacromolecules 2004, 5, 1141-1154. [CrossRef]

22. Lockhart, M.E.; Robbin, M.L.; Fineberg, N.S.; Wells, C.G.; Allon, M. Cephalic Vein Measurement before Forearm Fistula Creation: Does Use of a Tourniquet to Meet the Venous Diameter Threshold Increase the Number of Usable Fistulas? J. Ultrasound Med. 2006, 25, 1541-1545. [CrossRef]

23. Sandhu, N.P.S.; Sidhu, D.S. Mid-arm approach to basilic and cephalic vein cannulation using ultrasound guidance. Br. J. Anaesth. 2004, 93, 292-294. [CrossRef] [PubMed]

24. Anderson, C.B.; Etheredge, E.E.; Harter, H.R.; Codd, J.E.; Graff, R.J.; Newton, W.T. Blood flow measurements in arteriovenous dialysis fistulas. Int. J. Surg. Protoc. 1977, 81, 459-461.

25. Anderson, C.B.; Etheredge, E.E.; Harter, H.R.; Graff, R.J.; Codd, J.E.; Newton, W.T. Local blood flow characteristics of arteriovenous fistulas in the forearm for dialysis. Surg. Gynecol. Obs. 1977, 144, 531-533.

26. Kue, R.B.; Temin, E.S.; Weiner, S.G.; Gates, J.; Coleman, M.H.; Fisher, J.; Dyer, S. Tourniquet Use in a Civilian Emergency Medical Services Setting: A Descriptive Analysis of the Boston EMS Experience. Prehospital Emerg. Care 2015, 19, 399-404. [CrossRef] [PubMed]

27. King, R.B.; Filips, D.; Blitz, S.; Logsetty, S. Evaluation of Possible Tourniquet Systems for Use in the Canadian Forces. J. Trauma Inj. Infect. Crit. Care 2006, 60, 1061-1071. [CrossRef] [PubMed]

28. Kragh, J.F.; O’Neill, M.L.; Walters, T.J.; Dubick, M.A.; Baer, D.G.; Wade, C.E.; Holcomb, J.B.; Blackbourne, L.H. The Military Emergency Tourniquet Program's Lessons Learned with Devices and Designs. Mil. Med. 2011, 176, 1144-1152. [CrossRef] [PubMed] 